\title{
Salt- An Overview
}

\section{Aparna Nagendra ${ }^{1 *}$, Namratha Pramod ${ }^{2}$ and Seema Mukund ${ }^{3}$}

${ }^{1}$ Department of Nutrition and Dietetics, Bhagwan Mahaveer Jain Hospital, Girinagar,

Bengaluru, India

${ }^{2}$ Department of Nutrition, Sports Authority of India, Bengaluru, India

${ }^{3}$ Nutritionist, GOQii Hyderabad, India

*Corresponding Author: Aparna Nagendra, Senior Dietician, Department of

Nutrition and Dietetics, Bhagwan Mahaveer Jain Hospital, Girinagar, Bengaluru, India.

DOI: $10.31080 /$ ASNH.2020.04.0728
Received: July 01, 2020

Published: July 16, 2020

(C) All rights are reserved by Aparna

Nagendra., et al.

\begin{abstract}
Pythagoras stated "Salt is born of the purest parents - "The Sun and the Sea". Salt always takes the small but significant role in our diet. In this paper, we have mainly aimed on salt and its consumption. As it is the single common ingredient used across all cuisines in the world from ancient times and one the major element in the diet which plays a crucial role on health. It is generally called as 'Common Salt' and also widely used in the processing technology and preservation of foods. Due to urbanization and globalization, there has been a change in the eating pattern of the population, and adequate nutrition is essential for a healthy life. But, health effects are related to sodium which is linked with increased consumption of salt and it is one of the most important determinants of high blood pressure, cardiovascular risk and other diseases worldwide. This calls for creating awareness and educating the population regarding the daily salt consumption and also the hidden salt in various preserved foods. Encouraging on healthy eating pattern is the main criteria. An attempt was also made to introduce our readers to the different kinds of salts available in the shelves of supermarket.
\end{abstract}

Keywords: Salt; Sodium; Hypertension; Cardio Vascular Diseases; Preserved Foods and Processed Foods

\section{Introduction}

Salt is one of the most widely used ingredient in the kitchen on a day to day basis, hence it is called as 'Common Salt' and it is also widely used in the processing technology and preservation. Apart from food technology, salt plays a significant role in influencing the flavor of foods. It is a major ingredient in the dish without which everything seems to be taste less. There is a famous Kannada saying, which goes like 'there is no better best friend than mother, and there is no better ingredient than salt which can enhance the taste of the dish".

The chemical name of salt is Sodium Chloride and chemical formula is $\mathrm{NaCl}$ (1:1 Ratio of Sodium and Chloride ions). Salts are naturally found in sea water and the sodium chloride mineral halite which is also known as rock salt.

Salt is associated with many lifestyle related disease like hypertension, cardiovascular diseases [1] and contrarily, it is important for distinct physiological functions and essential for cellular homeostasis [2].

\section{History of salt}

Salt was a precious commodity that played an important part in the development of the ancient world. It was considered no less valuable than gold. Hence salt was also called as 'White Gold [3-5]. Salt being expensive was used as currency in ancient times. Those days, wages were paid in the form of salt in some countries. In fact, 
they word 'Salary' is derived from Salt itself (Latin word 'Sal'). The famous phrase "Not worth his salt" came to existence when the salary of the solider was cut if he failed to do his duties.

Before the invention of electricity or refrigerators, salt was used as the preservative for most of the foods such as meat and fish [6]. Salt was so valuable at one point in history that many city states waged wars over salt supplies and taxed the salt use of its citizens, and in addition it has created and destroyed many Empires [7]. Salt was scarce during the ancient times. It is said that during the French revolution, death penalty was issued for people who smuggled salt. In 1930 in India, "Salt Tax" was being collected by the British government to express monopoly against the salt production. Hence the famous 'Salt Satyagraha' was organized by Mahatma Gandhi to protest against the British Government [7]. There is no doubt that salt has seasoned history of mankind.

\section{Salt production}

The world's oceans have a virtually inexhaustible source of salt. In 2018, total world production of salt was 300 million tons, the top six producers being China (68 million), the United States (42 million), India (29 million), Germany (13 million), Canada (13 million) and Australia (12 million) [8].

Obtaining salt in modern days is an easy task than before. This is done using 3 main methods:

- Deep shaft mining: This is similar to mining for other minerals. The salt deposits from deep underground sea beds are mined about thousands of feet using this method. This type of mining mostly produces the "Rock Salt", majorly used in de-icing the walkways and high ways Extraction of Himalayan pink salt is done in this method [9].

- $\quad$ Solution Mining: This method is done by injection of fresh water to aid dissolving of salt from salt deposits. This method is similar to that used in oil and gas wells. The brine is then pumped out and taken to a plant for evaporation.

- Solar evaporation: Is the oldest method of salt production and is dependent on warmer climates. Salt is first captured in shallow ponds, where the wind and sun evaporate the water. Harvesting salt is done by hand or using a machine. Most table salt is produced with this method [10].

\section{Types of salt}

Salt is essential to the health of humans and other animals, and it is one of the five basic taste sensations [11] and it has an influ- ence on enhancing sweet tastes, improving the intensity and balance of overall flavor, increasing the sense of mouth feel and masking bitter tastes. Some types of Salts commonly used around the world are listed in the table 1.

\begin{tabular}{|c|c|}
\hline $\begin{array}{l}\text { Name of the } \\
\text { salt }\end{array}$ & Description \\
\hline $\begin{array}{l}\text { Himalayan } \\
\text { Pink Salt }\end{array}$ & $\begin{array}{l}\text { It is the purest form of salt in the world. It con- } \\
\text { tains almost } 84 \text { natural minerals and elements } \\
\text { found in the human body. Its mineral content } \\
\text { gives it a bolder flavor than many other salts. } \\
\text { Hence it is used as a cooking and finishing salt. It } \\
\text { retains temperature for hours. } \\
\text { It is harvested from Himalayan Mountains of } \\
\text { India and Pakistan. }\end{array}$ \\
\hline $\begin{array}{l}\text { Kala } \\
\text { (Bla }\end{array}$ & $\begin{array}{l}\text { Himalayan salt that's been packed in a jar with } \\
\text { charcoal, herbs, seeds and bark. Then fired in } \\
\text { a furnace for about } 24 \text { hours before it's cooled, } \\
\text { stored and aged. } \\
\text { It has a faint, sulfurous aroma of eggs. It's often } \\
\text { used in vegan and vegetarian dishes to give the } \\
\text { taste of egg, as well as used in ayurvedic practice. }\end{array}$ \\
\hline Table & $\begin{array}{l}\text { It is the most common salt used. It is harvested } \\
\text { from salt deposits found underground. Impuri- } \\
\text { ties and trace minerals removed in the process. } \\
\text { It's also treated with an anti-caking agent to } \\
\text { keep from clumping. }\end{array}$ \\
\hline Kitchen salt & $\begin{array}{l}\text { A coarse salt that is used in cooking but not at } \\
\text { the table }\end{array}$ \\
\hline Sea Salt & $\begin{array}{l}\text { Generic term for salt derived from evaporation } \\
\text { or reduction of sea water. Mineral content varies } \\
\text { with locally and drying process. }\end{array}$ \\
\hline Pickling salt & A non-iodized salt used for pickling and brining \\
\hline
\end{tabular}

Table 1: Different types of salts commonly used around the world. Source: Wikipedia.

\section{Salt and preservation}

Pythagoras stated "Salt is born of the purest parents - "The Sun and the Sea". Salt always takes the small but significant role in our diet. It is the single common ingredient across all cuisines in the world.

Preservation has been an age old method of food conservation. Since pre historic time preservation has been known to mankind. This method reduces the food spoilage by increasing the shelf life 
of the foods. It also helps to increase the food security over centuries. Process handling food and treating it to retard the growth of microbes is called preservation of food. It slows down the loss of quality, edibility and deterioration of the nutritive value of food. Preservation also maintains or preserves the texture and flavor of the food. Inhibiting the natural ageing and discoloration due to enzymatic browning reactions which are also a part of preservation.

\section{Different methods of preservation}

- Addition of natural additives like salt or sugar.

- Addition of micro-organisms like benign bacteria, fungi or yeast like in cheese and wines [12].

\section{Salting}

Salting is the oldest method of food preservation. Edible dry salt is used to preserve food in this method. Salted fish and salted meat are two ancient popular foods seen in history. Vegetables like beans and cabbages were also preserved using this method [13]. The associated flavors and taste of foods makes salting a popular method of preservation. Though salting is a famous and ancient method of preservation, the refrigeration usage has reduced this traditional practice of salting and on the other hand sodium levels are higher in processed foods which has a reduction in this method [14].

\section{Salt: As a preservative}

Salt dehydrates food by drawing the water out of the food. Absence of water seizes the growth of the microbes that can potentially cause spoilage of food. It also kills microbes by drawing water from the cells of the microbes itself, due to osmolarity difference or diffusion. High salt environment causes cell rupture of microbes and affects the enzymes and DNA of the microbes [15].

\section{Methods of salting}

- Curing: It is the simplest method of salt preservation. Curing is mostly done for meat, it is also known as corning.

- Brining: Foods are preserved under a salt solution. The flavors are not only preserved but enhanced during this process. Used for both meat and vegetables.

- Salt crusting: Foods that are needed to increase shelf life marginally use this method. Ex: Fish. Fish is layered with layers of salt and then used as fresh food for cooking later.

Salt has a prominent place in every day's diet especially in the cooked meals and usage of extra salt on table. A study showed salt consumption had increased in the studied individuals due to consumption of salted meat, salted fish, pickled vegetables etc. [16]. We Indians have higher consumptions of salt in the forms of pickles, preserved foods like papads, cereal crisps, and chutneys. Processed foods also have a lot of hidden salt either directly or in the form of preservatives. Most preserved foods have preservatives like sodium benzoate or sodium nitrates [17]. These processed foods are laiden with sodium, a main ingredient of salt. And globalization of food has made the imports of cereals and ready to eat foods which have a spike in the global market [18].

\section{Effects of increased consumption of salt on health}

In the $21^{\text {st }}$ century, changes were noted not only in the science and technology but also in the life-style of people [19]. A progression in nutritional transition has been detected in many developing countries [20]. It is believed that, over the years, people are consuming more unhealthy food and their food habits have also changed. Where, there is a shift from traditional diets rich in grains (dietary fiber), vegetables and fruits which are the major components of a healthy diet, being replaced by modern diets rich in fats (saturated fats, trans fats), sugars and salt. They choose to eat pizzas, burgers or chicken at food outlets [21]. Increasing production of more and more processed food, rapid urbanization and changing lifestyles are transforming people to adapt these dietary practices $[20,22]$ Another most common reason to replace traditionally home cooked foods may be the boost in economic status of individuals leading to higher buying capacity of ready to eat foods.

It is a well-known fact that, non-communicable diseases have been identified as one among the top ten threats to health in 2019 and are responsible for over $70 \%$ of the global deaths. The World Health Organization (WHO) Global Action Plan for the reduction of non-communicable diseases 2013-2020 has identified reducing the mean population sodium intake by $30 \%$ by 2025 as one of the nine priority voluntary global targets for the reduction of non-communicable disease [23]. India being a populous country of about 1.3 billion. The rising prevalence of lifestyle disorders in India is of concern as singly or in combination. Health effects related to sodium is associated with increased consumption of salt and it is one of the most important determinants of high blood pressure and increased cardiovascular risk worldwide [24]. Various literatures have shown that increased consumption of salt is associated with increased risk of hypertension [25,26], cardiovascular diseases (CVD) $[27,28]$ and stroke $[29,30]$ and chronic kidney disease [31]. 


\section{Hypertension}

Increased blood pressure (BP) is the major cause of death and disability in adults worldwide [32] and it is ranked the third most important risk factor for attributed to the burden of disease in south Asia (2010) [33]. According to the World Health Organization (WHO), in 2015, raised BP was responsible for 7.5 million deaths, about 12.8 per cent of the total of all deaths globally [34] and the data from Global Burden of Diseases (GBD) study of 2016, hypertension led to 1.63 million deaths in India in the year 2016 alone [35]. Sodium is essential in regulating blood volume, blood pressure, osmotic equilibrium and $\mathrm{pH}$, but excess intake of dietary sodium (salt) leads to fluid retention and subsequent rise in blood pressure [36]. There is an overwhelming evidence from a wide variety of studies which have shown a consistent direct relationship between salt intake and blood pressure [32]. This is consistent in both experimental animal models and human studies [26,37]. Population-based interventions indicate that when salt intake is reduced, blood pressure in the community falls. A moderate reduction in the salt intake is therefore recommended worldwide for the prevention and control of high blood pressure [24].

\section{Salt and fluid balance}

Salt is one of the major component contributing to the total body fluid balance. High intake of salt causes thirst and increased fluid intake that is then retained in the intravascular compartment causing an increase in total blood volume. Both heart and the kidney are the main organs to compensate for these changes. Dysregulations of these systems may lead to fluid retention that can be aggravated by high salt intake and ameliorated by a reduction in salt intake [38].

\section{Cardio vascular diseases}

Cardiovascular diseases are the leading cause of death globally. An estimated 17.8 million people died from CVDs in 2017 [39]. Evidence from a wide variety of studies shows a consistent direct relationship between salt intake and blood pressure. Effects of sodium intake on vascular hemodynamics showed that, a high sodium intake and the increase in blood pressure levels are related to water retention, increase in systemic peripheral resistance, alterations in the endothelial function, changes in the structure and function of large elastic arteries, modification in sympathetic activity, and in the autonomic neuronal modulation of the cardiovascular system [40]. The risk of cardiovascular disease increases with increasing blood pressure and a reduction in blood pressure causes a significant reduction in vascular events [24]. Thus, a reduction in dietary sodium not only decreases the blood pressure and the incidence of hypertension, but is also associated with a reduction in morbidity and mortality from cardiovascular diseases.

\section{Chronic kidney disease}

Chronic kidney disease (CKD) is associated with cardiovascular disease and high blood pressure being a major risk factor for both. Generally, salt sensitivity is reported to be more prevalent in patients with CKD due to a reduced ability to excrete sodium, which may lead to increased blood pressure. Although there is evidence linking high sodium intake with high blood pressure, but there is not enough evidence that a low sodium restriction protects against or causes better outcomes of CKD than a moderate sodium restriction [41]. A study by Carlo Garofalo., et al. (2018) on 734 CKD (stage 1-4) patients concluded that moderate salt restriction significantly reduces blood pressure and proteinuria/albuminuria in patients with CKD [42].

\section{Stroke}

Stroke is one of the silent but leading causes of mortality. The risk factors for stroke include hypertension, coronary heart diseases, diabetes and obesity, where in hypertension is the top risk factor [43]. Excess salt (sodium chloride) intake has a major role in the pathogenesis of elevated BP. There are substantial evidence supporting a direct relationship between sodium intake, cardiovascular diseases and stroke. Recent trials on lifestyle interventions that were focused on reduced sodium intake have reported significant effects on cardiovascular diseases and stroke outcomes in general populations. This evidence is consistent with indirect evidence on the benefits of reducing sodium intake on blood pressure. Dr Hong-shuo SUN, a Canadian Stroke Network researcher, commented that it is important to educate the general population on reduction of dietary salt intake to approximately $1500 \mathrm{mg} /$ day. Especially in aged people it can reduce the risk of stroke which will have a significant impact on preventing stroke and thus reducing overall morbidity and mortality of cardiovascular diseases and stroke $[43,44]$.

\section{Osteoporosis}

The amount of calcium that the body loses via urination increases with the amount of salt consumed. Insufficient calcium in the blood, can leach out of the bones. Hence, a diet high in sodium has an additional unwanted effect which is the bone-thinning disease known as osteoporosis [45]. A study by Birgit., et al. (2008) showed that, salt was responsible for a significant change in bone calcium 
balance, from positive to negative, when consumed as part of a high calcium diet, but with a low calcium intake, the bone calcium balance was negative on both high and low salt diets [46].

\section{Cancer}

Gastric cancer or stomach cancer remains one of the most common and deadly cancers worldwide. Based on GLOBOCAN 2018 data, stomach cancer is the $5^{\text {th }}$ most common neoplasm and the $3^{\text {rd- }}$ most deadly cancer, with an estimated deaths of 783,000 in 2018 [47]. A majority of the epidemiological studies shows positive evidence for an association between salt or salted food consumption and stomach cancer risk, which was also supported by experimental studies. Since salt intake has been correlated with Helicobacter pylori ( $H$ pylori) infection, it is also possible that these two factors may collaborate to promote the development of stomach cancer [48]. The overall results from studies are not very consistent, but based on the available experimental and epidemiological data, the World Cancer Research Fund and American Institute for Cancer Research concluded that salt, as well as salted and salty foods, are a "probable cause of stomach cancer [49]. Ideally, modification of salt in the diet along with elimination of $H$. pylori infection, is a favorably promising strategy for gastric cancer prevention throughout the world.

\section{Salt recommendations}

Salt contains both sodium and chlorine which is chemically known as "sodium chloride". It is commonly used to flavor and preserve foods. In fact, salt is the main source of sodium in the diet, which is essential for the body to function normally. The requirement for sodium in the body is much less than the amount usually eaten. Data presented by the National Nutrition Monitoring Bureau (NNMB) indicates that salt consumption ranges from 5 to 30 grams in different states of India [50].

- For adults: WHO recommends that adults consume less than $5 \mathrm{~g}$ (just under a teaspoon) of salt per day.

- For children: WHO recommends that the recommended maximum intake of salt for adults be adjusted downward for children aged two to 15 years based on their energy requirements relative to those of adults. This recommendation for children does not address the period of exclusive breastfeeding (0-6 months) or the period of complementary feeding with continued breastfeeding (6-24 months).

- All salt that is consumed should be iodized or "fortified" with iodine, which is essential for healthy brain development in the fetus and young child and optimizing people's mental function in general [22].

- $1 \mathrm{~g}$ of sodium Chloride (Nacl) contains contain 39\% Sodium [51]. Table 2 gives the sodium content in some processed foods.

\begin{tabular}{|l|c|}
\hline Food product & Sodium content per 100 gm \\
\hline Papad & $4000 \mathrm{mg}$ \\
\hline Instant noodles & $2486 \mathrm{mg}$ \\
\hline Ready to eat meals & $1400 \mathrm{mg}$ \\
\hline Ready to eat soup & $5378 \mathrm{mg}$ \\
\hline Sauce & $2400 \mathrm{mg}$ \\
\hline Ketchup & $907 \mathrm{mg}$ \\
\hline Mango pickle & $5433 \mathrm{mg}$ \\
\hline Soft drinks & $4 \mathrm{mg}$ \\
\hline Canned tomatoes & $132 \mathrm{mg}$ \\
\hline
\end{tabular}

Table 2: Sodium content present in some processed foods. Source: Georgia institute for global health, USDA.

\begin{tabular}{|c|c|}
\hline Categories & Strategies to Reduce Salt in Dietary Practices \\
\hline $\begin{array}{l}\text { Fruits and } \\
\text { Vegetables }\end{array}$ & $\begin{array}{l}\text { Avoid canned fruits and vegetables. } \\
\text { Rather consume more fresh fruit and veg- } \\
\text { etables. (They are naturally low in calories and } \\
\text { salt. They are also rich in potassium, and help } \\
\text { decrease blood pressure) }\end{array}$ \\
\hline $\begin{array}{l}\text { Processed } \\
\text { and Pre- } \\
\text { served foods }\end{array}$ & $\begin{array}{l}\text { Limiting consumption of processed meats - sau- } \\
\text { sages and salami. } \\
\text { Avoid Sea foods - dry fish, prawns } \\
\text { Avoid canned and tinned foods like: tomato } \\
\text { sauce or ketchups } \\
\text { Reduce intake of dehydrated foods such as sea- } \\
\text { soning mixes and soups. } \\
\text { Swap salty foods like salted nuts, potato chips, } \\
\text { pickles, papads, chutneys, mixtures, salted } \\
\text { breads and baked foods with healthy choices. } \\
\text { Consume fruit, salad, low fat yoghurt or low-salt } \\
\text { crackers/biscuits or popcorn }\end{array}$ \\
\hline $\begin{array}{l}\text { Convenience } \\
\text { Foods }\end{array}$ & $\begin{array}{l}\text { Limiting take-away foods. } \\
\text { Promote use of traditional food rather than } \\
\text { western or fast food and junk foods which are } \\
\text { high not only in salt but also in calories, sugar } \\
\text { and fat content. }\end{array}$ \\
\hline Beverage & $\begin{array}{l}\text { Avoid carbonated beverages or aerated drinks } \\
\text { and packed soups } \\
\text { Quit or reduce your alcohol intake. Limit con- } \\
\text { sumption to no more than two drinks per day } \\
\qquad(30 \mathrm{ml})\end{array}$ \\
\hline $\begin{array}{l}\text { Spices and } \\
\text { Flavorings }\end{array}$ & $\begin{array}{l}\text { Flavoring foods with herbs and spices instead } \\
\text { of salt. } \\
\text { Salt can be substituted with lime, lemon juice, } \\
\text { garlic or pepper. } \\
\text { To refrain from adding salt on table. } \\
\text { Choose and prepare foods in less salt. }\end{array}$ \\
\hline
\end{tabular}

Table 3: Recommendations to reduce excessive salt in the diet. 


\section{Physical activity}

- WHO recommends engage in regular aerobic physical activity such as brisk walking at least 30 - 45 minutes/day or 150 minutes of moderate-intensity or 75 minutes of vigorous-intense physical activity per-week, gardening for 30 - 45 minutes, bicycling, swimming laps for 20 minutes [52-54].

- $\quad$ Mind-body therapies (Yoga, meditation).

- You can even divide the 30 minutes into shorter periods of at least 10 minutes each for instance: Use stairs instead of an elevator, get off bus one or two stops early, or park your car at the far end of the lot at work. It helps reduce risk of chronic diseases and manage weight.

\section{Conclusion}

Technological advancements have simplified the work and lifestyle of the people and it is one of the primary factors for nutritional transition. As always, unhealthy food is absolutely associated to taste. But, adequate nutrition is essential for a healthy life. Thus, identifying the risk factors and correction plays a major role. And sodium which is consumed in the form of salt, is an essential component of the body which is directly related to many chronic diseases. Salt occupies a central place as it is a minor but important element of food. Thus, it becomes important to be conscious about the daily requirements of sodium as suggested by the WHO standards. As the risk factors of today are stated to be the diseases of tomorrow, it is important to make proper food choices ultimately to maintain health and wellbeing.

\section{Bibliography}

1. Aburto NJ., et al. "Effect of lower sodium intake on health: Systematic review and meta-analyses". British Medical Journal 346 (2013): f1326.

2. Farquhar WB., et al. "Dietary sodium and health: More than just blood pressure". Journal of the American College of Cardiology 65 (2015): 1042-1050.

3. Kurlansky M. "Salt: A World History". New York, USA: Penguin Books (2003): 496.

4. Brown IW. "Salt: White gold of the Maya". Journal of Field Archaeology 28 (2001): 457-459.

5. Kennedy CM. "The other white gold: Salt, slaves, the Turks and Caicos Islands, and British colonialism". The Historian 69 (2007): 215-230.
6. Buss David Robertson Jean. Manual of Nutrition. Her Majesty's Stationery Office. (1973): 37-38.

7. Kurlansky, Mark. "Salt: A World History". Penguin Books (2003).

8. Bolen Wallace P. "Salt" (PDF). US Geological Survey, Mineral Commodity Summaries (Report). US Geological Survey (2019).

9. Pennington, Matthew. "Pakistan salt mined old-fashioned way mine". The Seattle Times (2005).

10. Alberger process. Manufacture of salt: Uses of artificial heat. Encyclopædia Britannica online (2011).

11. The sense of taste (2013).

12. Hamid A., et al. "Food: Its preservatives, additives and applications".

13. "Historical Origins of Food Preservation". University of Georgia, National Centre for Home Food Preservation (2018).

14. Strategies to Reduce Sodium Intake in the United States.

15. Institute of Medicine (US) Committee on Strategies to Reduce Sodium Intake Henney JE, Taylor CL, Boon CS, editors. Washington (DC): National Academies Press (US) (2010).

16. Ingrid Koo. PhD Using Salt as a Food Preservative. (2020).

17. Loreta Strumylaitè., et al. Salt-preserved foods and risk of gastric cancer Laboratory of Preventive Medicine, Institute for Biomedical Research, Kaunas University of Medicine, Lithuania.

18. Marshall Brain. How Food Preservation Works.

19. S Banshi S., et al. "Prevalence of Obesity and Overweight in Housewives and its Relation with Household Activities and Socio economical Status". Journal of Obesity and Medical Research 1 (2014): 20-24.

20. Aparna Nagendra., et al. "Nutritional Status Screening of Doctors and Nurses of Selected Hospitals in Bengaluru". Acta Scientific Nutritional Health 4.4 (2020): 50-56.

21. Ramona Rischke., et al. "Supermarkets and food consumption patterns: The case of small towns in Kenya". Food Policy 52 (2015): 9-21.

22. "Salt reduction: fact sheet". World Health Organization (2016). 
23. Rachael M., et al. "Science of Salt: A regularly updated systematic review of salt and health outcomes studies (April to October 2018)". Clinical Hypertens 21 (2019): 1030-1042.

24. Francesco P Cappuccio. "Cardiovascular and other effects of salt consumption”. Kidney International 3.4 (2011): 312-315.

25. Intersalt Cooperative Research Group. "Intersalt: An international study of electrolyte excretion and blood pressure. Results for $24 \mathrm{~h}$ urinary sodium and potassium excretion". British Medicine Journal 297 (1988): 319-328.

26. Khaw KT., et al. "Blood pressure and urinary sodium in men and women: The Norfolk Cohort of the European Prospective Investigation into Cancer (EPIC-Norfolk)". The American Journal of Clinical Nutrition 80 (2004): 1397-1403.

27. Tuomilehto J., et al. "Urinary sodium excretion and cardiovascular mortality in Finland: A prospective study". Lancet 357 (2001): 848-851.

28. Yang Q., et al. "Sodium and potassium intake and mortality among US adults: Prospective data from the third National Health and Nutrition Examination Survey". Archives of International Medicine 171 (2011): 1183-1191.

29. Nagata C., et al. "Sodium intake and risk of death from stroke in Japanese men and women". Stroke 35 (2004): 1543-1547.

30. Li XY., et al. "High salt intake and stroke: Meta-analysis of the epidemiologic evidence". CNS Neuroscience and Therapeutics 18 (2012): 691-701.

31. Chobanian AV., et al. "The Seventh Report of the Joint National Committee on Prevention, Detection, Evaluation, and Treatment of High Blood Pressure: the JNC 7 report". JAMA 289.19 (2003): 2560-2572.

32. He FJ., et al. "Effect of longer term modest salt reduction on blood pressure: Cochrane systematic review and meta-analysis of randomized trials". BMJ 346 (2013): f1325.

33. Lim SS., et al. "A comparative risk assessment of burden of disease and injury attributable to 67 risk factors and risk factor clusters in 21 regions, 1990-2010: a systematic analysis for the Global Burden of Disease Study 2010". Lancet 380 (2012): 2224-2260.

34. World Health Organization. Global Health Observatory (GHO) data.
35. Gakidou E., et al. "Global, regional, and national comparative risk assessment of 84 behavioural, environmental and occupational, and metabolic risks or clusters of risks, 1990-2016: A systematic analysis for the Global Burden of Disease study 2016". Lancet 390 (2017): 1345-422.

36. Appel LJ., et al. "The importance of population-wide sodium reduction as a means to prevent cardiovascular disease and stroke: a call to action from the American Heart Association". Circulation 123 (2011): 1138-1143.

37. He FJ and MacGregor GA. "Reducing population salt intake worldwide: from evidence to implementation". Progress in Cardiovascular Diseases 52.5 (2010): 363-382.

38. Missouris CG., et al. "Diuretics and oedema: how to avoid rebound sodium retention". Lancet 339 (1992): 1546.

39. https://www.who.int/elena/titles/sodium_cvd_adults/en/

40. Andrea Grillo., et al. "Sodium Intake and Hypertension". Nutrients 11.9 (2019): 1970.

41. Smyth A., et al. "Sodium intake and renal outcomes: a systematic review". American Journal of Hypertension 27.10 (2014): 1277-1284.

42. Carlo Garofalo., et al. "Dietary Salt Restriction in Chronic Kidney Disease: A Meta-Analysis of Randomized Clinical Trials". Nutrients 10.6 (2018): 732.

43. Ekaterina TURLOVA., et al. "Dietary salt intake and stroke". Acta Pharmacologica Sinica 34 (2013): 8-9.

44. Cook NR., et al. "Long term effects of dietary sodium reduction on cardiovascular disease outcomes: observational followup of the trials of hypertension prevention (TOHP)". BMJ 334 (2007): 885-888.

45. He FJ and MacGregor GA. "A comprehensive review on salt and health and current experience of worldwide salt reduction programmes". Journal of Human Hypertension 23.6 (2009): 363.

46. Birgit Teucher., et al. "Sodium and Bone Health: Impact of Moderately High and Low Salt Intakes on Calcium Metabolism in Postmenopausal Women". American Society for Bone and Mineral Research 23 (2008): 1477-1485.

47. Prashanth Rawla and Adam Barsouk. "Epidemiology of gastric cancer: global trends, risk factors and prevention". Gastroenterology Review 14.1 (2019): 26-38. 
48. Wang XQ., et al. "Salt consumption and stomach cancer". World Journal of Gastroenterology 15.18 (2009): 2204-2213.

49. World Cancer Research Fund, American Institute for Cancer Research. Food, Nutrition, Physical Activity, and the Prevention of Cancer: A Global Perspective. London (2007).

50. https://foodsafetyhelpline.com/know-recommended-dailyallowance-sodium/

51. Revised RDA for Indians 2010. National Institute of Nutrition (ICMR). Hyderabad.

52. World Health Organization, Europe. "Coronavirus disease (COVID-19) outbreak". Stay physically active during self-quarantine.

53. The George Institute for global health. Salt content of processed foods in India (2016).

54. USDA.

\section{Assets from publication with us}

- Prompt Acknowledgement after receiving the article

- Thorough Double blinded peer review

- Rapid Publication

- Issue of Publication Certificate

- High visibility of your Published work

Website: www.actascientific.com/

Submit Article: www.actascientific.com/submission.php

Email us: editor@actascientific.com

Contact us: +919182824667 